\title{
Risk Factors and Syndromic Management of Sexually Transmitted Infections among Sex Workers in the Kadiolo Circle
}

\author{
Diarra Aminta ${ }^{*}$, Cissoko Yacouba ${ }^{2}$, Konate Issa ${ }^{2}$, Matchim Kouam Clemence ${ }^{2}$, \\ Samake Dramane ${ }^{3}$, Traore Madou${ }^{4}$, Daou Sounkalo² \\ ${ }^{1}$ Support and Counseling Care Unit for People Living with HIV/AIDS Dermatology Hospital, Bamako, Mali \\ ${ }^{2}$ Infectious and Tropical Diseases Department of the University Hospital of Point G, Bamako, Mali \\ ${ }^{3}$ Mopti Regional Hospital, Mopti, Mali \\ ${ }^{4}$ Sikasso Regional Hospital, Sikasso, Mali \\ Email: ^aminata191@yahoo.fr
}

How to cite this paper: Aminta, D., Yacouba, C., Issa, K., Clemence, M.K., Dramane, S., Madou, T. and Sounkalo, D. (2021) Risk Factors and Syndromic Management of Sexually Transmitted Infections among Sex Workers in the Kadiolo Circle. Advances in Infectious Diseases, 11, 95-103.

https://doi.org/10.4236/aid.2021.112011

Received: February 8, 2021

Accepted: March 30, 2021

Published: April 2, 2021

Copyright (c) 2021 by author(s) and Scientific Research Publishing Inc. This work is licensed under the Creative Commons Attribution International License (CC BY 4.0).

http://creativecommons.org/licenses/by/4.0/

\begin{abstract}
Sexually transmitted infections constitute a gateway for the human immunodeficiency virus by the presence of ulcerations and local inflammatory manifestations, thus increasing the risk of transmission. The aim of the study was to assess the sexual behavior and syndromic management of sexual infections among female sex workers in the Kadiolo circle. Material and method: This was a descriptive cross-sectional study carried out in the Kadiolo circle from January 1 to December 31, 2014. It focused on clandestine or posted sex workers, aged 15 and over. Results: We collected 465 sex workers aged 15 and 49, aged 26.6 on average and from Ivory Coast 52\%, Nigeria $26.2 \%$ and Mali 9.7\%. Educational attainment was higher with $2.4 \%$. Posted sex workers represented $92.5 \%$ and housed in brothels with a stay of 6 months with $53.3 \%$. They were single with $70.8 \%$ of cases and about $72.9 \%$ lived alone and without a spouse. The age at first sexual intercourse was between 15 - 19 years with $76.6 \%$ of cases. The number of first commercial sex was between $15-19$ years (26\%) and 20 - 24 years (45.8\%). Usual condom use with regular sex partners was $22.1 \%$. Condom use was almost compulsory at $89.7 \%$ with occasional clients or non-regular sexual partners. The average number of clients per day was five (5). The major reason for consultation was vaginal discharge $16.4 \%$ followed by abdominal pain. The human immunodeficiency virus test was not compulsory and only 86 workers or $18.5 \%$ accepted with a positive result of 11 people or $12.8 \%$ of cases. Conclusion: Sexually transmitted infections are
\end{abstract}


common especially as they affect young people.

\section{Keywords}

Sex Worker, Kadiolo, Infectious Disease

\section{Introduction}

The couple sexually transmitted infection and infection with the human immunodeficiency virus remain a major public health problem in our countries. Sexually transmitted infections are a gateway for the human immunodeficiency virus by the presence of ulcerations and local inflammatory manifestations, thus increasing the risk of transmission [1] [2]. In the mid-1980s, sexually transmitted infections declined dramatically. Since 1998 there has been an increase in the number of cases of classic sexually transmitted infections such as syphilis, gonorrhea, and since 2003, lymphogranulomatosis venereal in patients infected with the human immunodeficiency virus, especially in the homosexual population [3] [4]. The World Health Organization estimates that approximately one million people contract a sexually transmitted infection, including HIV, per day [5]. An estimated 375 million people each year contract one of the following four sexually transmitted infections: trichomoniasis, gonorrhea, chlamydia and syphilis [6]. In Mali, according to the 2006 demographic health survey, the prevalence of sexually transmitted infections was estimated at $6 \%$ among women with a high prevalence of $10 \%$ in Bamako. Men were less affected (3\%) than women (6\%) [7]. The global prevalence of human immunodeficiency virus infection was estimated according to the 2014 organization of united nations/AIDS global report at 35 million people worldwide, including 24.1 million in sub-Saharan Africa, thus representing $70 \%$ of people living with the human immunodeficiency virus [8]. In Mali, this prevalence was $1.1 \%$ [7]. The Sikasso region is home to many gold panning areas in which workers outside their activities and far from their families constitute a group at risk of associating with sex workers. Their surveillance remains important for the protection of the surrounding population by stopping the transmission of sexually transmitted infections and the human immunodeficiency virus. We thought that it would be wise to assess the risk behaviors and the quality of syndromic management of sexually transmitted infections among sex workers in the Kadiolo circle.

\section{Material and Method}

This was a descriptive cross-sectional study carried out in the Kadiolo circle from January 1 to December 31, 2014 during which we included 465 workers aged 15 years. Kadiolo (Sikasso region), is a circle in Mali bordering the Ivory Coast. Traditional gold mining is the main activity in the area with a mobile population. The volunteers were sex workers who came for consultation at the 
health center. After obtaining informed consent, they were included in the study.

Inclusion criteria: These were women aged over 15, sex workers and resident in the Kadiolo circle and were not included women under 15 and those who were not recognized as sex workers.

\section{Judgement criteria:}

All women aged 15 and over, sex workers and residents of Kadiolo.

The presence of a genital ulceration, vaginal discharge, or other evidence of a genital infection on physical examination.

The presence of an infectious syndrome such as a genital ulceration, vaginal discharge, or other sign of a genital infection on physical examination.

Human immunodeficiency virus serology was used to screen sex workers with HIV.

The Gonadotropic Chorionic Hormone test was used to check for pregnancy in female sex workers.

\section{Sample size}

Joséphine Aho [9] in 2011 carried out a study of 421 sex workers in Conakry, Republic of Guinea in three stages, and we extended our study over one year in order to increase our statistical power to cover seasonal mobility.

\section{The data collector}

The data was collected during a confidential interview and recorded in a questionnaire. This questionnaire was drawn up by the scientific officer and the principal investigator and included;

The statistical population studied was sex workers.

The variables studied were:

- Quantitative included the desired risk factors such as the age of sex workers, age of first sexual intercourse and commercialization and length of stay in brothels and also the number of clients per day.

- Qualitative included marital status, level of study, occupation, condom use. The clinical data collected were the reason for consultation, the result of the human immunodeficiency virus serology screening and those of pregnancy as well as the type of infectious syndrome.

The questionnaire was subjected to a stimulus test on the recruitment procedure and data analysis.

The questionnaire was subjected to a daily quality control before it was entered.

The Excel 2016 software was used for data entry and then analyzed by the SPSS 24 software. The static test used was the ki2 with a significance level of 5\%.

Ethics: The informed consent of each of the participants and the preservation of medical confidentiality were the rule.

\section{Results}

We collected 465 female sex workers aged 15 to 49 . The 20 - 29 age group was the most represented, $60.4 \%$ with an average of 26.6 years (Table 1 ). The majority of patients came from neighboring countries of Mali, in particular from the Ivory Coast 52\%, Nigeria 26.2\%, and Burkina Faso with $8.8 \%$. Malians made 
up $9.7 \%$ of the workforce. Patients had completed higher education in $2.4 \%$ of cases and $46.7 \%$ were out of school. They displayed their profession in $92.5 \%$ and they were housed in brothels with a stay of 6 months in $53.3 \%$ of cases. Those who worked clandestinely $(7.5 \%)$ had other daily activities and were mainly represented by saleswomen, $71.4 \%$, and hairdressers, $14.3 \%$. These sex workers were predominantly single, i.e. $70.8 \%$, and approximately $72.9 \%$ lived alone and without a spouse.

The age of the first sexual intercourse was in the age group 15 - 19 years with $76.6 \%$ of cases with an average of 16.33 years (Table 2). The number of first commercial sex was between 15 - 19 years (26\%), 20 - 24 years (45.8\%) and over 30 years $(9.7 \%)$ (Table 3$)$. Usual condom use with regular sex partners was $22.1 \%$ of cases, and more than half of these regular sex partners engaged in unprotected sex. Condom use was almost compulsory at $89.7 \%$ with occasional clients or non-regular sexual partners (Table 4). The number of clients varied from day to day with an average of 5 clients and extremes of 0 to 11 .

Clinically, the major reason for consultation was vaginal discharge $16.4 \%$ followed by abdominal pain and genital ulceration.

The human immunodeficiency virus test was not compulsory and only 86 workers or $18.5 \%$ accepted with a positive result of 11 people or $12.8 \%$ of cases. Sexually transmitted infections accounted for $33.2 \%$ or about 15 workers and largely dominated by vaginal discharge at $80 \%$ and abdominal pain at $20 \%$ (Table $5)$. The majority of these infections were diagnosed in workers with a high number of sexual partners, varying between 6 and 10 per day. Unintended pregnancies were $3.3 \%$ of cases. Syndromic management of sexually transmitted infections was etiologically consistent with the WHO management algorithm with $18.5 \%$ of cases.

Table 1. Distribution of sex workers by age group.

\begin{tabular}{ccc}
\hline Age & Number & Percentage \\
\hline $15-19$ years & 35 & 7.5 \\
$20-24$ years & 182 & 39.1 \\
$25-29$ years & 99 & 21.3 \\
$30-34$ years & 90 & 19.4 \\
$35-39$ years & 28 & 6 \\
$>40$ years & 31 & 6.7 \\
Total & 465 & 100 \\
\hline
\end{tabular}

The age group 20 - 24 was the majority with $39.1 \%$.

Table 2. Distribution of sex workers by age group at first intercourse.

\begin{tabular}{ccc}
\hline Age at first sexual intercourse & Numbers & Percentage \\
\hline Under 14 years & 69 & 14.8 \\
$15-19$ years & 356 & 76.6 \\
$20-24$ years & 38 & 8.2 \\
25 years and over & 2 & 0.4 \\
Total & 465 & 100 \\
\hline
\end{tabular}

The age of first sexual intercourse was $14.8 \%$ for those under 14 . 
Table 3. Distribution of sex workers by age group of first commercial sex.

\begin{tabular}{ccc}
\hline Age of first commercial intercourse & Number & Percentage \\
\hline Under 14 years & 1 & 0.2 \\
15 - 19 years & 121 & 26.0 \\
20 - 24 years & 213 & 45.8 \\
25 - 29 years & 85 & 18.3 \\
30 - 34 years & 28 & 6.0 \\
35 - 39 years & 10 & 2.2 \\
40 and over & 7 & 1.5 \\
Total & 465 & 100 \\
\hline
\end{tabular}

The age group 40 and over was $1.5 \%$ to have first commercial sex.

Table 4. Systematic condom use by sexual partners.

\begin{tabular}{ccc}
\hline Systematic condom use by sexual partners & Number & Percentage \\
\hline Yes & 417 & 89.7 \\
Often used condom & 35 & 7.5 \\
No & 13 & 2.8 \\
Total & 465 & 100 \\
\hline
\end{tabular}

Consistent condom use with non-regular sexual partners was $89.7 \%$.

Table 5. Distribution of sex workers according to the nature of the infectious syndrome.

\begin{tabular}{ccc}
\hline Infectious syndromes & Number & Percentage \\
\hline Abnormal vaginal discharge & 12 & 80 \\
Abdominal pain & 3 & 20 \\
Genital ulceration & 2 & 13.3 \\
Genital itching or burning & 2 & 13.3 \\
\hline
\end{tabular}

The most common infectious syndrome encountered was abnormal vaginal discharge with $80 \%$.

\section{Discussion}

This descriptive study made it possible to determine the frequency of risk factors for sexually transmitted infections among sex workers in Kadiolo. During this study, we encountered difficulties in recruiting sex workers; this difficulty was overcome by the use of networks in the field. The most represented age group was that of $20-29$ years or $60.4 \%$ according to data from Aho J. in Guinea Conakry $61.3 \%$ [10]. This could be explained by the working age group, the existence of a strong demand for sexual service, the conditions of poverty experienced by women and finally the extraordinary economic interests. Thus, the perpetuation of prostitution is firstly due to the fact that there is a demand for it. Without clients, there is no prostitution [11]. The economic principle of supply and demand finds its application in this context. Indeed, without men in search of sexual pleasures, prostitution could not exist [11] [12]. Foreign nationality was in the majority $90.3 \%$ with an Ivorian predominance (52\%). This large 
presence of sex workers of foreign origin is in agreement with the literature [12] [13]. The strong representativeness of foreigners could be explained by the fact that the sex trade is strongly condemned by the Malian religious and administrative authorities with a stigmatization of young girls from the locality for having expressed themselves in this activity. Foreigners are less complex because they practice away from their families and their usual social environment. The sex workers in our study were $46.7 \%$ out of school due to the low rate of schooling in our country. Singles were in the majority in our study at $70.8 \%$. The sex trade being an unethical activity and strongly condemned by Malian society, the young woman needs all her freedom of action to carry out her activity; therefore any legal attachment would constitute an obstacle. However, the presence of a proportion of married sex workers could be due to the fact that most do not live regularly with their husbands and therefore work underground to avoid social confrontation and family rejection. The age of the first sexual intercourse varied between 15 and 19 years or $76.6 \%$ of our sample with an average of 16.33 years in agreement with the data of SIDIBE O, 62.3\% [13], but lower than that suggested by WHO ( $\geq 21$ years). This result could be justified by the fact that at this age of adolescence the young girl undergoes significant bodily and behavioral transformations and at the same time discovers sexuality. The cultural context of our country greatly influences sex education which remains a taboo subject in our families. The majority of sex workers, $45.8 \%$, had their first commercial sex between the ages of 20 and 24 in response to poverty, the responsibilities of life and independence of personal care. Prostitution becomes an easy opportunity to face these needs, especially since it can be carried out in parallel with other activities in accordance with the literature [11] [12] [13] [14]. Some sex workers (27.1\%) lived with a spouse who could be either a husband, a boyfriend, a partner, a regular client. This indicates the clandestine nature of the fact that apart from this activity some lead an almost normal life. Wearing a condom was a function of the type of partner and often of the choice imposed by the client, making this profession a source of dissemination of sexually transmitted infections because the regularity of the partner does not guarantee his fidelity [15] [16]. Most of the sex workers surveyed had recently arrived in establishments inherent in their activities. Thus our study found a strong representativeness of $53.3 \%$ for the duration of $0-6$ months. The low representativeness for a long time could be explained by the daily violence, insecurity and abandonment motivated by the regaining of consciousness with the shame of oneself, Sexually transmitted infections accounted for $33.2 \%$ or about 15 workers and largely dominated by vaginal discharge syndrome at $80 \%$ and abdominal pain $20 \%$ thus increasing the occurrence of serious gynecological complications. Sexually transmitted infections were higher among sex workers who received a high number of clients making the trade a risk factor for infection [3] [4]. People starting out and/or working occasionally are likely to be less informed about prevention due to greater isolation. They are also exposed to special requests 
from certain clients who wish to obtain sex close to those that take place outside of prostitution, that is, without a condom.

Syndromic management of sexually transmitted infections was consistent with the national algorithm in $18.5 \%$ of cases. This rate is low compared to that of South Africa where it ranges from $36 \%$ to $67 \%$ [17]. This is said to be because they have guidelines for the management of sexually transmitted infections. On the other hand, in Papua New Guinea, syndromic management of sexually transmitted infections was low, estimated at between 7\% and 9\% [18]. This demonstrates the need for new policies for the management, monitoring and control of sexually transmitted infections to reduce transmission of human immunodeficiency virus.

\section{The Encountered Difficulties}

- Lack of mastery of the French language and local languages, some English-speaking participants did not want to participate in the study and the information was collected with difficulty by those who participated in the study.

- The date of birth was provided by the participant without any possibility of verification.

- The dates of the first sexual and commercial intercourse were provided by the participants without any possibility of verification.

- The participants estimated the average number of clients per day.

- For moral reasons, some married women did not want to participate in the study.

\section{Conclusion}

Sexually transmitted infections are common and more serious, especially in young people. Adequate management is necessary to prevent the transmission and spread of these infections. Prevention involves sex education and sensitization of young people, especially sex workers.

\section{Acknowledgements}

We thank the administrative authorities of the Kadiolo circle for completing the administrative and regulatory formalities for this work, as well as the study population for their trust.

\section{Conflicts of Interest}

The authors declare no conflicts of interest regarding the publication of this paper.

\section{References}

[1] Holmes, K.K., Sparling, P.F., Stamm, W.E., et al. (2008) Sexually Transmitted Diseases. 4th Edition, McGraw-Hill, New York, 575-606. 
[2] Organization of United Nations/AIDS (2006) Update on the AIDS Epidemic: Joint United Nations Program on HIV/AIDS Version. 64-67.

[3] Yéni, P., Blanche, S., Bourdillon, F., Bourlière, M., Brun-Vézinet, F., Chêne, G., et al. (2008) Medical Care for People Infected with HIV. Recommendations of the Expert Group. Medicine-Sciences Flammarion, Paris, 412.

[4] Janier, M., Girard, P.M., Katlama, C. and Pialoux, G. (2007) Sexually Transmitted Diseases and HIV Infection 2007. Doin, Paris, 173-181.

[5] WHO (2019) Sexually Transmitted Infections. http://www.who.int/mediacentre/factsheets/fs110/fr/\#content

[6] Laurent, C., Seck, K., Coumba, N., Kane, T., et al. (2003) Prevalence of HIV and Other Sexually Transmitted Infections, and Risk Behaviors in Unregistered Sex Workers in Dakar, Senegal. AIDS, 17, 1811-1816. https://doi.org/10.1097/00002030-200308150-00010

[7] Demographic and Health Survey: EDS IV Mali 2006.

[8] Organization of United Nations/AIDS (2013) 2014 Fact Sheet.

[9] Aho, J. (2011) HIV Prevention among Female Sex Workers in Conakry, Republic of Guinea: Voluntary Testing Counseling, Risky Behaviors and Sexually Transmitted Infections. Thesis Sté pub, Montreal, $245 \mathrm{p}$.

[10] Louis, M.V. (2000) Towards the Legal Commodification of the Human Body? No to Pimping Europe. Femmes Info, No. 89, Winter, 8.

[11] Murphy, L.S. (2010) Understanding the Social and Economic Contexts Surrounding Women Engaged in Street-Level Prostitution. Issues in Mental Health Nursing, 31. 775-784. https://doi.org/10.3109/01612840.2010.524345

[12] Slim, M., Haddad, C., Sfeir, E., Rahme, C. and Hallit, S. (2020) Obeid S Factors Influencing Women's Sex Work in a Lebanese Sample: Results of a Case-Control Study. BMC Womens Health, 20, Article Number: 193. https://doi.org/10.1186/s12905-020-01062-x

[13] Sidibé, O. (2013) Assessment of Risk Behaviors and STI and HIV/AIDS Syndromes among Sex Workers Attending the Services of the Non-Governmental Organization SOTURA in Bamako. Thesis Medicine Bamako.

[14] Ly, F., Guéye, N., Samb, N.D., Sow, P.S., Ndiaye, B. and Mahé, A. (2006) Prospective Study of Sexually Transmitted Infections in Dakar. Medicine Tropical, 66, 64-68.

[15] Ahojo, A.B., Alary, M., Meda, H., Ndour, M., Batoma, G., Biterab, R., et al. (2007) Integrated Surveillance Survey of HIV and Other Sexually Transmitted Infections among Sex Workers in Benin in 2002. Cahiers Sante, 17, 143-151.

[16] Campeau, L., Blouin, K., Leclerc, P., Alary, M., Morissette, C., Blanchette, C., Serhir, B., et al. (2018) Impact of Sex Work on Risk Behaviors and Their Association with HIV Positivity among People Who Inject Drugs in Eastern Central Canada: Cross-Sectional Results from an Open Cohort Study. BMJ Open, 8, e019388. https://doi.org/10.1136/bmjopen-2017-019388

[17] Van der Eem, L., Dubbink, J.H., Struthers, H.E., McIntyre, J.H., Ouburg, S., Morré, S.A., et al. (2016) Evaluation of Syndromic Management Guidelines for Treatment of Sexually Transmitted Infections in South African Women. Tropical Medicine \& International Health, 21, 1138-1146. https://doi.org/10.1111/tmi.12742

[18] Vallely, L.M., Toliman, P., Ryan, C., Rai, G., Wapling, J., Gabuzzi, J., et al. (2017) Performance of Syndromic Management for the Detection and Treatment of Genit- 
al Chlamydia trachomatis, Neisseria gonorrhoeae and Trichomonas vaginalis among Women Attending Antenatal, Well Woman and Sexual Health Clinics in Papua. BMJ Open, 7, e018630. 